\title{
S.I.G. para a Gestão de Custos por Qualidade: Estudo de Caso em uma Cooperativa de Café
}

\author{
Luciel Henrique de Oliveira
}

\section{RESUMO}

Os Sistemas de Informação Gerenciais (SIG) utilizados nas cooperativas de café normalmente controlam apenas as quantidades estocadas por tipo de café, não controlando seus custos. Consideram como custo a média dos preços de compra de café, em determinado período, impossibilitando o conhecimento do verdadeiro custo dos blends vendidos, de acordo com sua qualidade e margem de lucro. Assim, o resultado real das operações só é conhecido quando analisado um longo período, porque sofre influência das flutuações dos vários tipos de café comprados e vendidos. Este trabalho estuda um caso real, e apresenta um SIG que integra a gestão de estoques com o gerenciamento de custos de café por qualidade, através do Custeio Baseado em Atividades. Parte-se de uma visão ampliada da empresa no mercado, considerandose que a cooperativa pode utilizar lotes de café do cooperado para posterior compra ou devolução de produto da mesma espécie. Integrando-se os controles de estoques da cooperativa e dos cooperados, físico e "virtual" com o mercado consumidor, é possível o controle e o planejamento da comercialização mais eficiente para a redução dos riscos da cooperativa.

Palavras-chaves: sistemas de informação gerencial, gestão integrada de custos, café, gestão de cooperativas.

\begin{abstract}
The Executive Information Systems (EIS) used in Brazilian coffee co-operatives usually control only the quantitative stock by kind of coffee and do not control specific costs. So they consider the average of the purchases prices in a determined period, thus rendering impossible to know the blends real cost according to their quality. Therefore the real result of the operations is known only if a long period is analyzed, because it is influenced by fluctuations of several coffee kinds purchased and sold. The chief purpose of this paper is to investigate a real case in a large Brazilian coffee co-operative; it proposes a model for an EIS component, aiming to integrate the stock management with management of cost by quality, using the concept of an activity based cost. From an amplified view of the enterprise in the market, we consider that the co-operatives may use associated coffee batches for later purchase or devolution of a same species product. In this way, integrating the co-operative stock control with the correspondent portions of the associated partners, it is possible to get a more efficient control and planning of the market in view of the cooperative risks reduction.
\end{abstract}

Key words: executive information systems, integrated costs management, agribusiness, coffee, co-operative management. 


\section{INTRODUÇÃO}

\section{Origem e Importância do Trabalho}

Em 1997 o agribusiness do café vive um período favorável, apresentando altas constantes de preços, devido à pequena safra do país, à pequena disponibilidade de café estocado e ao aumento de consumo no Brasil e em quase todos os países compradores. O país apresenta atualmente um consumo anual de 12 milhões de sacas, e há expectativas de atingir 15 milhões até o ano 2.000. Em maio/97, os produtores estavam eufóricos, por estarem recebendo cerca de US\$230,00/saca. Este cenário, que se seguiu a uma época de crise e de preços baixos (nos primeiros anos da década de 90 , quando os preços médios estiveram em torno de US $\$ 45,00$ / saca), evidenciou nas cooperativas de produtores a necessidade de melhor controle operacional e financeiro, visando à melhoria dos processos gerenciais, para permitir maior competitividade nos mercados internos e externos.

Os Sistemas de Informação Gerenciais (SIG), tradicionalmente utilizados nas cooperativas de produtores de café, envolvem sistemas de controle de estoque e análise de custos, mas controlam apenas as quantidades estocadas por tipo de café, não controlando seus custos. Normalmente consideram como custo a média dos preços de compra de café, em determinado período. Assim impossibilitam o conhecimento do verdadeiro custo do produto vendido, de acordo com sua qualidade e margem de lucro, em cada operação de venda. Logo, o resultado real das compras e vendas de café só é conhecido quando analisado um longo período, porque sofre influência das flutuações dos vários tipos de café que são comercializados.

Este trabalho iniciou-se com a constatação da necessidade de integrar o sistema de controle de estoques e custos, estruturado basicamente em controles de estoque padrão. As principais questões que regem as operações comerciais de café pelas cooperativas podem ser assim caracterizadas: 1) os produtos armazenados no estoque, na maioria das vezes, não são propriedade da cooperativa; são propriedade dos cooperados, que podem vendê-los à cooperativa ou retirá-los a qualquer momento; 2) não há atribuição de preços porque o produto oscila a preço de mercado, não sofrendo depreciação por tempo de estocagem; 3) a atividade da cooperativa é de comprar, processar e vender café no mercado interno ou externo; 4) as suas vendas de café são dedicadas às necessidades de seus clientes, enquanto as suas compras se vão adequando às necessidades de seus cooperados; 5) por uma questão operacional de armazenagem, ou mesmo pelo fato de a cooperativa 
não possuir em seu estoque próprio um determinado tipo de café, pode utilizar um lote de café do cooperado para posterior compra ou devolução de produto da mesma espécie.

\section{Objetivos do Trabalho}

Elaborar um Sistema de Informação Gerencial (SIG) para a gestão de estoques que possibilite gerenciar custos de café de acordo com sua qualidade. Este trabalho constitui uma primeira abordagem, como idéia para ser discutida e ampliada, e desenvolve os principais pontos:

- visão ampliada da gestão empresarial, considerando o trabalho dentro e fora da empresa;

· aplicação destes conceitos à uma cooperativa de produtores;

- o desafio da melhoria contínua da qualidade da gestão, através da visão integrada da empresa e do conhecimento real das estruturas de estoques e custos envolvidas;

- proposta de um SIG para melhor controle das operações, dos custos dos produtos vendidos, de acordo com sua qualidade e margem de lucro, em cada operação de venda, possibilitando um melhor planejamento da comercialização pela cooperativa.

\section{Apresentação da Organização Estudada}

A Cooperativa Regional dos Cafeicultores em Guaxupé - Cooxupé, com sede em Guaxupé, sul de Minas Gerais, é a maior cooperativa privada de café do mundo. Possui atualmente cerca de 7.000 associados e 1.100 funcionários. Instalada em uma região que produz cerca de 2,6 milhões de sacas por ano, a Cooxupé recebe e comercializa a produção de seus associados, equivalente a 1,3 milhão de sacas por ano em uma área de 212.500 hectares plantados com café. Este volume representa hoje 1,4\% da produção mundial e 6,5\% da produção brasileira. É o $9^{\circ}$ maior grupo agropecuário do Brasil em faturamento, e o $5^{\circ}$ colocado entre os exportadores de café, com embarques para o exterior da ordem de 900 mil sacas por ano. A qualidade de seu produto lhe garante participação ativa no mercado internacional, com destaque para Alemanha, Itália, Holanda, Bélgica, Estados Unidos e Japão, conhecidos por sua sofisticação e exigência de paladar.

Distribuídos em 12 núcleos de operação, a Cooxupé conta com 10 armazéns para recebimento, preparo e padronização do café. Estes núcleos prestam serviços de assistência técnica, e comercializam café e cereais. Cada núcleo tem loja para o fornecimento de insumos agrícolas e equipamentos que apóiam a produção. 
As atividades com o café somam 54,7\% do faturamento da Cooxupé. Este percentual inclui também uma torrefação. A segunda maior parcela do faturamento, $27 \%$, fica com as lojas. Suas outras unidade de negócio incluem a avicultura, que detém $4,0 \%$ do faturamento, produzindo 4,2 milhões de frangos por ano através de um regime de integração com os cooperados. A produção de rações responde por $7,0 \%$ do faturamento e a comercialização de 60 mil toneladas de milho por ano soma outros $3,0 \%$. Cumprindo seu papel de prestadora de serviços à produção agrícola de sua área de abrangência, a cooperativa tem nas atividades de transporte, armazenagem e silo para cereais, com capacidade estática de 15 mil toneladas, $3,0 \%$ de seu faturamento. Por último, há ainda a produção de hortifrutigranjeiros, que representa $1,3 \%$ do faturamento.

\section{SIG para uma Gestão Empresarial InTEGrada}

\section{Características das Organizações Cooperativas}

Cooperativa é uma sociedade de pessoas, de natureza civil, unidas pela cooperação e ajuda mútua, gerida de forma democrática e participativa, com objetivos econômicos e sociais comuns e cujos aspectos legais e doutrinários são distintos de outras sociedades (OCEMG, 1994). Fundamenta-se na economia solidária e se propõe obter um desempenho eficiente, através da qualidade e da confiabilidade dos serviços que presta a seus próprios associados e seus usuários.

A função do sistema cooperativista é apresentar a melhor alternativa de comercialização para os cooperados, não podendo haver conflitos entre os interesses da "empresa" e dos seus cooperados (sócios). Os "Princípios Cooperativistas" constituem os fundamentos da doutrina cooperativista, fazem de uma cooperativa uma organização que exige administração diferenciada, e podem ser assim resumidos:

- Adesão livre e estímulo à educação permanente dos membros;

- controle democrático: cada associado tem direito a um voto, não importando o seu capital integralizado, e as decisões representam a vontade da maioria;

- neutralidade política e indiscriminação religiosa, racial e social;

- retorno das sobras proporcional às operações;

- juros limitados ao capital: a lei 5.764/71 permite que a cooperativa pague até $12 \%$ de juros sobre o capital integralizado pelo associado. É uma forma de incentivo ao associado, pois a cooperativa não tem a finalidade de remunerar o capital social; 
• integração cooperativista: espírito de união e cooperação mútua de seus membros.

\section{Dinâmica da Informaçăo nas Empresas}

O desempenho eficiente, através da qualidade e da confiabilidade dos serviços que presta a seus cooperados, é o produto final do sistema cooperativista. Este processo depende de informações preexistentes e atualizadas, e por sua vez gera novas informações, que servem de ponto de partida para análise de desempenho e para o planejamento de suas ações futuras.

Até os anos 70, o processo de geração de informações empresariais evoluía em ritmo contínuo mas moderado. Os executivos dispunham de tempo para analisar a interrelação das informações sobre o desempenho de suas empresas com o fluxo de informações geradas nas pesquisas, consultorias e análises conjunturais. Estas análises permitiam o redirecionamento das estratégias da empresa e o aproveitamento de novas tendências e oportunidades de negócios. Nos anos 80 iniciouse um processo de transformação marcado pelo avanço da Tecnologia de Informação. Empresas pioneiras organizaram seus CPD`s; bibliotecas universitárias começavam a automatizar seus acervos. A informática possibilitava armazenamento e recuperação mais eficiente das informações geradas.

O paradigma dominante confere alta prioridade à produtividade e ao desenvolvimento tecnológico com a finalidade de colocar mais e melhores quantidades de informação em menores e mais produtivos espaços de memória artificial (Barreto, 1994). Embora as empresas tenham aumentado suas capacidades tecnológicas, mantém-se ainda forte identificação com a tradicional "custódia" e uso da informação; esta concepção permanece vigente até hoje.

\section{Informação como Recurso Estratégico para a Ação}

A afirmação de que informação é um recurso tem dois significados distintos: por um lado, ressalta sua importância nas empresas e valoriza o trabalho dos profissionais da área; por outro, mostra que é necessário aplicar as técnicas tradicionais de gestão de recursos - planejamento, organização, direção e controle - à informação (Eaton e Bawden, 1991; Glazer, 1993; Cornella, 1994).

As empresas que quiserem liderar a competição na "sociedade da informação" devem atuar como "organizações inteligentes", transformando os problemas que enfrentam em soluções sobre as bases que elas conheçam ou possam conhecer (Páez Urdaneta, 1994). Devem aprender com os problemas e experiências, adquirindo assim um arsenal de informações estratégicas que lhes permitam enfrentar as ameaças do ambiente empresarial. 
É necessário repensar a "dimensão da informação" nas organizações. Isto implica admitir a idéia de que a informação é recurso organizacional e que como tal deve ser incluído na administração. A definição de "recurso de informação" não deve ficar limitada aos documentos oficiais e contábeis das organizações, qualquer que seja seu porte, mas deve também incorporar todos os tipos de recursos formais e informais que são gerados e utilizados no dia-a-dia das empresas, como bases de dados institucionais, documentos textuais e não textuais, diretórios, bases numéricas, etc (Horton, 1991). Assim, entramos em uma dimensão mais complexa do fenômeno da informação nas organizações. Esta abordagem é identificada na literatura como "Administração da Informação"; é definida por Páez Urdaneta (1994) como o "manejo da inteligência corporativa de uma organização com o objetivo de aumentar seus níveis de eficiência, eficácia e efetividade no cumprimento de suas metas".

O uso da informação como recurso estratégico para a ação exige a determinação das necessidades internas e externas de informação e sua satisfação; o desenvolvimento da base informacional da organização e a garantia de acesso a ela. Para isto, a organização deve otimizar o fluxo das informações e o nível de comunicações e desenvolver a estrutura informacional, garantindo a sua operacionalidade. $\mathrm{O}$ desafio à gerência é manejar eficientemente os recursos institucionais de informações, melhorar os seus investimentos sucessivos e otimizar seu aproveitamento; ademais, otimizar o aproveitamento da base e da estrutura informacional da organização, para aumentar sua produtividade e o retorno dos investimentos. Para tal, deve-se continuamente educar e treinar os membros da organização no manejo e na utilização dos recursos informacionais. Os SIG consistem no uso da tecnologia de informação, para suportar a estratégia competitiva da organização, e permitir um planejamento que aumente sua vantagem competitiva (Cohen, 1996).

\section{Gestão Empresarial Integrada}

É cada vez mais evidente o reconhecimento dado pelas empresas à importância de ter todos os processos organizacionais integrados e orientados de acordo com um objetivo estratégico corporativo. A Gestão Empresarial Integrada vê a integração de processos como algo mais do que simplesmente derrubar barreiras departamentais; além disso, procura integrar tanto recursos tecnológicos quanto humanos em busca de maior qualidade e produtividade organizacional. Considera-se que a empresa deve ser competitiva no ponto onde possui habilidades e recursos suficientes, bem como conhecimento técnico. Isto faz com que a empresa procure explorar seu ponto forte, ou seja, o aspecto chave para seu desenvolvimento e conseqüente aumento de competitividade no seu mercado de atuação. 
A única forma de se obter a integração total da empresa é pela otimização das interfaces entre todos os principais processos que a compõem. Deve-se estabelecer as fronteiras entre cada um deles e os objetivos respectivos a serem alcançados para que a organização se desenvolva como um todo. De acordo com esses conceitos, antes de se optar por qualquer tipo de processo ou técnica de reestruturação organizacional, deve-se fazer uma análise criteriosa da empresa, delineando aspectos relativos tanto ao seu ambiente interno quanto externo. A empresa deve saber com clareza qual é seu objetivo estratégico, fato este de extrema relevância no sucesso de um processo de mudança. Todos os outros objetivos específicos a cada processo devem estar em consonância com a estratégia organizacional, de maneira que todos os esforços estejam direcionados para o mesmo foco de ação.

Rentes et al. (1996) propõem uma Metodologia de Integração de Empresa, visando alcançar esta integração através do uso de um conjunto de modernas técnicas e conceitos administrativos, a partir da análise da realidade do ambiente interno e externo da organização. A metodologia proposta envolve as seguintes etapas:

(1) Levantamento de Requisitos e Diagnóstico da Situação Atual: com objetivo de obter uma visão geral da empresa, através do conhecimento de suas estratégias, fatores críticos de sucesso e forma atual de operação (Aguiar et al., 1994);

(2) Especificação de Projeto: baseado na seleção de Ações de Integração definidas junto à empresa. Envolve a Reengenharia e Simplificação de Reorganização Empresarial; a Formalização de Procedimentos de Qualidade; a Seleção de Soluções; o Desenvolvimento de Soluções e a Definição de Customização e Desenvolvimentos;

(3) Implementação e Monitoração: detalhamento, implantação e manutenção dos os projetos de modernização. Envolve a Implantação de Processos e Sistemas e a Melhoria Contínua.

A partir dos resultados da fase de Reengenharia ou Simplificação, tem-se o subsídio necessário para a aplicação de conceitos do Custeio Baseado em Atividades - Activity Based Costing - ABC (Berliner e Brimson, 1988). A fase de Gestão Total de Custos consiste na definição de atividades e seus direcionadores de custo.

O desafio maior é que os projetos sejam implantados de forma integrada, eliminando-se a repetição de esforços e garantindo que as ações ocorram dentro das diretrizes estratégicas previamente definidas. Este conjunto de proposições estabelece novo modelo de operação. Este deverá ser apoiado por um sistema de informação coerente com os novos paradigmas da empresa, que será diferente do atual. 


\section{Agribusiness do Café: Características, Dimensăo e Competitividade}

A expressão agribusiness designa o complexo processo que engloba o mercado de insumos e fatores de produção, passa pela empresa rural (unidade de produção), e vai até o processamento, a transformação, o armazenamento, a distribuição e a comercialização dos produtos finais. Assim, representa a soma total de todas estas operações, englobando os fornecedores de bens e serviços para a agropecuária, os produtores rurais, os processadores, transformadores e distribuidores envolvidos na geração e no fluxo dos produtos até o consumidor final. Participam também deste processo os agentes que coordenam o fluxo dos produtos, como o Governo, os mercados, as entidades financeiras, comerciais e de serviços (Araújo, Wedekin e Pinazza, 1990). Todos os segmentos envolvidos geram e demandam grande quantidade de informações, que precisam estar sempre atualizadas e disponíveis na hora e na forma em que se fizerem necessárias para a operacionalização das transações.

O agribusiness ou Complexo Agroindustrial (CAI) é um sistema integrado. Uma cadeia de negócios, pesquisa, estudos, ciência, tecnologia, informação, etc, desde a origem vegetal/animal até produtos finais com valor agregado, no setor de alimentos, fibras, energia, têxtil, energia, bebidas, couro... (Megido, 1997). O estudo deste complexo revela que não existe mais agricultura comercial sem tecnologia.

Segundo Kageyama et al. (1987), a partir da constituição dos CAI's, o desenvolvimento da agropecuária passa a depender da dinâmica da indústria. Não se pode mais considerar a agropecuária como setor isolado da economia, pois grande parte das atividades do que era antes considerado "setor primário da economia" integrou-se na matriz de relações inter-industriais, sendo seu funcionamento determinado de forma conjunta. Assim, não há mais uma dinâmica geral da agropecuária, mas várias dinâmicas próprias de cada um dos complexos particulares.

O agribusiness abrange todas as operações de produção e distribuição de suprimentos agropecuários; as operações de produção no campo; o armazenamento, processamento e distribuição dos produtos agropecuários e dos itens produzidos a partir deles, constituem um sistema único, com cada setor dependendo profundamente do outro. Daí decorre a extrema necessidade de informações prontamente atualizadas e disponíveis para garantir a maior eficiência e eficácia no desenvolvimento das operações dos agronegócios.

A Figura 1 ilustra os segmentos integrantes do Complexo Agroindustrial do Café (CAC) e suas interrelações. Os cafeicultores, individualmente ou em grupos, produzem o "café em coco", que pode ser comercializado desta maneira, ou beneficiado. Dependendo da região em que se encontram, da qualidade e da quan- 
tidade do café, os produtores têm a opção de vender o produto para uma cooperativa, para os corretores, ou diretamente para os exportadores. As cooperativas reúnem um volume maior do produto e assim têm maior poder de negociação do preço junto aos corretores e/ou exportadores. Às vezes a própria cooperativa pode ser exportadora.

Figura 1: Esquema do Complexo Agroindustrial do Café (CAC)

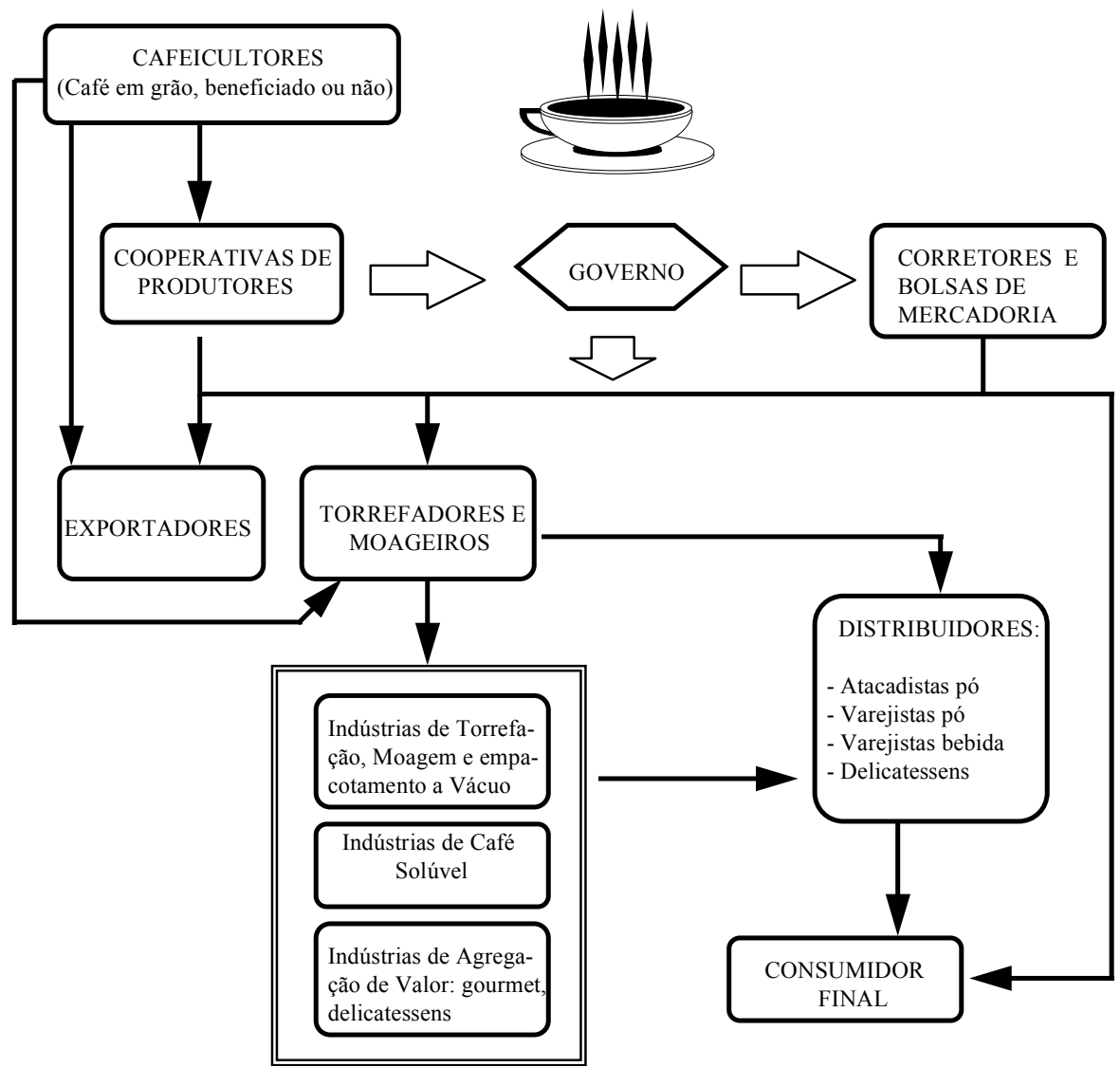

Fonte: Adaptado de Soares (1980, p.36). 
Apesar de não haver relação direta, o governo está sempre orientando o mercado de café no país, podendo eventualmente atuar em medidas diretas através da liberação de seus estoques reguladores. Às vezes, políticas são mal formuladas, interferindo negativamente no agribusiness do café. Tome-se como exemplo o caso do Governo da Colômbia, que investiu cerca de US\$ 2 bilhões, ao longo de 20 anos em marketing e qualidade de seu café, e mesmo assim perdeu, em 1996, $14,6 \%$ de receita, pelo aumento de custos internos como taxa de juros, inflação e valorização do peso (moeda nacional), em face do dólar (Megido, 1997).

Todos os segmentos relacionam-se com os torrefadores e moageiros. Eventualmente cooperativas e exportadores podem ser também torrefadores e moageiros. Este segmento vende o café já torrado e moído para as indústrias processadoras em maior escala. Geralmente existem várias pequenas torrefadoras, e algumas grandes indústrias, que acabam comprando o produto das primeiras. O setor industrial do café envolve as grandes indústrias de torrefação e empacotamento a vácuo, as indústrias de café solúvel e as indústrias de agregação de valor, que trabalham com a produção de cafés finos, com aroma, concentração e sabores diferentes (gourmet e delicatessens). Todos os segmentos, finalmente, vendem o produto aos atacadistas e varejistas, que vendem aos consumidores finais.

A comercialização do café exige sua classificação e padronização. A classificação do café é bastante detalhada, sendo feita por Tipos, de 2 a 8 , segundo normas da Tabela Oficial Brasileira de Classificação (IBC, 1985); por Qualidade (dos grãos e da bebida); pela Variedade (Arábica e Robusta); e pelo Porto de exportação, na classificação comercial do produto, como por exemplo: Santos (SP), Paranaguá (PR), Vitória (ES), Rio de Janeiro (RJ), etc.

A maior parte do café comercializado pela Cooxupé é da variedade Arábica, produzidos na região sul de Minas Gerais, no norte se São Paulo e no cerrado mineiro. No entanto existe pequena parcela da variedade Robusta, ou Conilon, produzida principalmente no Espírito Santo, que origina uma bebida tida como de qualidade inferior.

Para determinar a qualidade de um café, são analisados os diversos fatores que determinam seu grau de aceitação pelo mercado consumidor. Os principais são: bebida, grão, peneira, aspecto, cor, seca, preparo e torração. Na maioria dos mercados as demais características do café não influem de maneira tão acentuada no valor do produto como a qualidade da bebida. Existe uma classificação tradicional pela bebida, com termos consagrados pelo uso. Normalmente todo comprador pergunta se o café "bebe bem". "Beber bem", significa um café com bebida "dura" para melhor e "beber mal", quando é de "riada" para pior. O café de bebida 
"mole" tem sabor agradável, brando e doce. A bebida "dura", tem gosto acre, adstringente e áspero; entretanto esse café não tem sabor estranho. O café "riado" salienta-se com um leve sabor típico de iodofórmio, cujo aroma lembra este produto químico (Carneiro Filho, 1989).

A Cooxupé utiliza um sistema próprio de classificação por qualidade, identificando os diferentes tipos de café com uma classificação em R.A.'s (Remessa de Amostra). Além disso, ainda há a classificação pelo tamanho do grão (por peneiras). Assim, a cooperativa trabalha com cerca de 35 tipos de café por qualidade, mas neste trabalho o sistema proposto agrupa os tipos de café semelhantes e que possuem o mesmo preço de mercado. Assim, a classificação pode ser resumidos em 14 grupos, em ordem decrescente de qualidade da bebida que originam: RA1 (o café mais fino - padrão exportação), RA2, RA3, RA4, RA5, RA6, RA8, RA10, RA11, RA12, RA44, RA CONI (variedade Conilon), RA ESC (escolha), RA PALHA.

\section{Gestão de Custos do Café por Qualidade}

\section{Descrição do Caso Analisado - Antecedentes}

O Sistema de Comercialização da Cooxupé atua em dois mercados: no Mercado Externo, realizado diretamente com os compradores, que são clientes diretos, através de comerciantes e/ou distribuidores, e no Mercado Interno, comercializando com Indústrias, torrefações e outros exportadores. A formação do preço de venda é feita pelas condições de mercado. O preço é ditado pelas indústrias, produtores, comerciantes e pelas Bolsas de Mercadorias, no mercado futuro.

A Cooxupé controla os estoques de café próprio e de cooperados, através de uma conta opção, que trata de negócios liquidados (café comprado pela cooperativa). Se a cooperativa compra café dos cooperados, assume o risco. No entanto pode operar tanto com o café comprado dos produtores quanto com o não comprado. Esta possibilidade dá liquidez à cooperativa que trabalha dentro de um limite fixado para negociação, em função do risco. Isto é controlado pelo saldo opção, que é a diferença entre o estoque de café da cooperativa e o dos cooperados. Para a cooperativa é mais importante ganhar na unidade do que especular com o preço do café, aumentando o risco. O controle de estoque disponível, dos produtos comprados e vendidos, é que forma a conta opção. O desconhecimento das características dos tipos de café, que compõem o controle de estoque físico e que fazem flutuar a conta opção, pode capitalizar ou descapitalizar a empresa. 
Ao conhecê-los, as flutuações desta conta poderão ser gerenciadas com maior autonomia, e esta é a proposta do SIG apresentado neste trabalho.

O risco aumenta com a possibilidade de ocorrer um problema de "caixa" com a conta opção: impasse que pode ocorrer, se em determinado dia ou semana a cooperativa comprar maior quantidade de café fino (tipo RA1, por exemplo) e vender mais café barato (de qualidade inferior, tipo RA4, por exemplo). Neste caso, a conta opção pode estar positiva em volume, mas com saldo financeiro negativo, em virtude de ter comprado produto de alto valor e vendido produto de valor menor. O controle de estoque utilizado atualmente não consegue identificar esses casos. O sistema em uso pela cooperativa não possui mecanismos, informações e parâmetros para avaliar a eficiência do negócio realizado. Por outro lado, não se conhece o custo real do produto, trabalha-se apenas em termos médios, não se diferenciando por qualidade; desse modo, não se conhece a margem de contribuição de cada tipo de blend comercializado.

Considera-se que os seguintes mecanismos podem melhorar a performance da comercialização na Cooxupé: o custeio $\mathrm{ABC}$, para dar nova visão gerencial do que mais agrega valor para a cooperativa, no mercado interno e externo; e a desvinculação da comercialização com o custo médio (fixo) do café. Apesar destas medidas, o custo ainda sobe, principalmente devido ao impacto dos tributos. Estão controladas as despesas diretas, mas há fortes impactos em outras áreas (externas, indiretas). Assim, a alternativa de trabalhar com o custeio $\mathrm{ABC}$ parece representar uma solução viável, e é esta a proposta do sistema de informações gerenciais desenvolvido.

Para que o café possa ser exportado é necessário que seja "padronizado", de modo a atender os mercados consumidores mundiais, cada dia mais competitivos e exigentes de qualidade. Esse fato faz com que a cooperativa procure sempre atualizar suas instalações de máquinas, as mais modernas e eficientes, e o café pode ser preparado com maior perfeição. Há hoje na cooperativa 44 máquinas eletrônicas, para seleção ("catação") de café, trabalho que antigamente era feito manualmente. Essas máquinas conseguem, pela diferenciação de cor, rejeitar os grãos defeituosos como verdes, pretos, "ardidos", etc, que depreciariam o lote. Com esse conjunto de eletrônicas e mais uma série de máquinas destinadas à limpeza e separação por peso e tamanho dos grãos, a cooperativa consegue padronizar 5.000 sacas de café diariamente. A cooperativa dispõe ainda, para prestar serviços ao cooperado, principalmente ao pequeno produtor, instalações para seca e benefício de café. O produtor, conforme o nível de sua produção, pode colher o café e enviá-lo para a cooperativa, que irá fazer todas operações subseqüentes. 


\section{Processos Operacionais do Café na Cooperativa}

\section{Figura 2: Fluxograma de Operações para o Preparo do Café na Cooperativa}

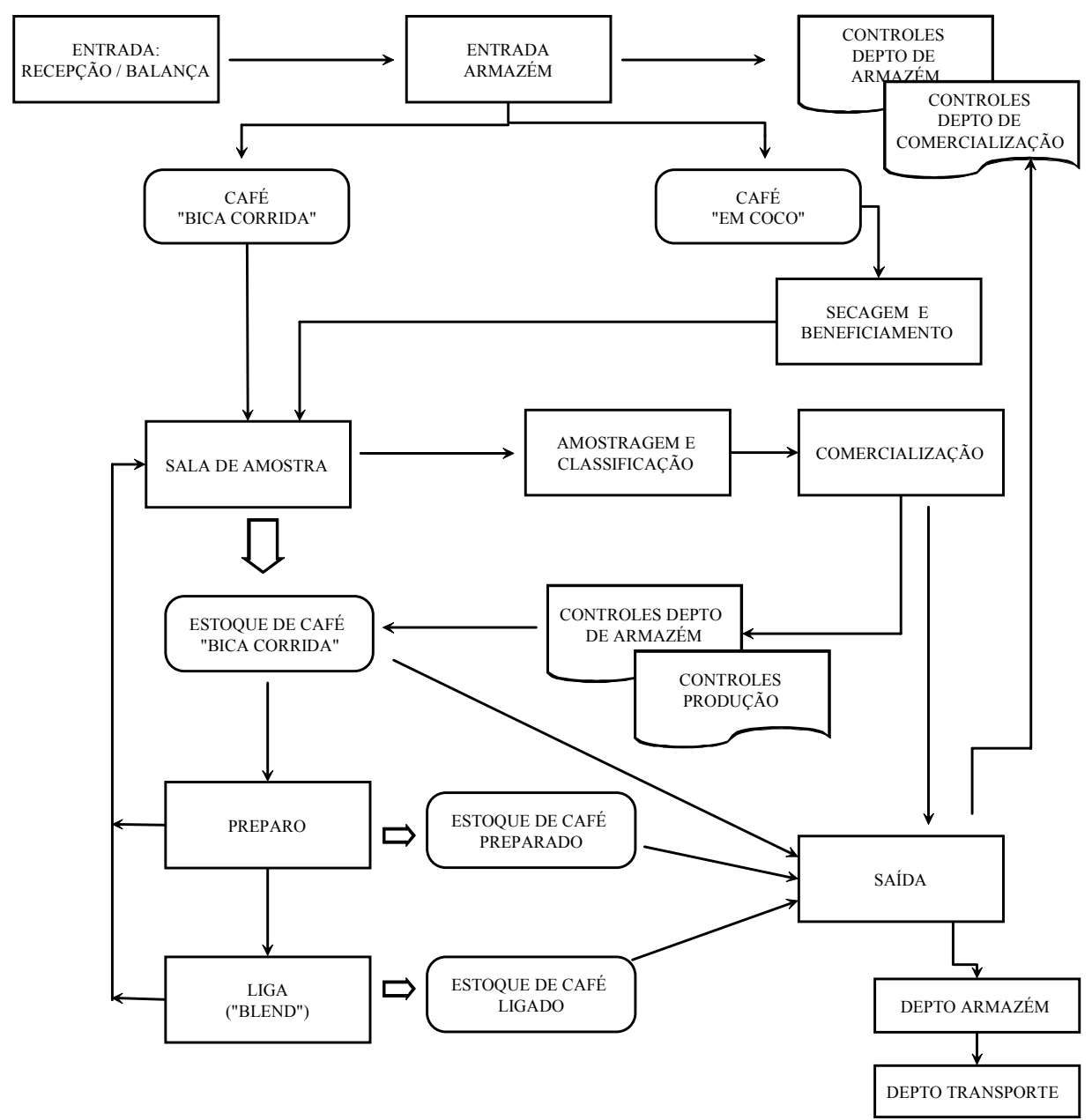

Fonte: Dados da Pesquisa. 
A Cooxupé recebe café dos produtores, que pode ser em coco (não beneficiado, o que se dá em pequena quantidade) e "bica corrida", termo que designa o café despolpado e beneficiado, mas não preparado. A seguir a cooperativa procede ao seu "preparo", que significa sua classificação e separação em componentes principais de acordo com a categoria de classificação. A Figura 2 mostra o fluxograma resumido das operações de preparo de café pela cooperativa, desde o recebimento do produtor até a sua venda, que pode ser de café "bica corrida" (em pequena proporção), ou de café preparado ou ligado (blends).

No processo de preparo do café, a cooperativa realiza a separação do café "bica corrida", recebido do produtor, nas seguintes partes:

- R.A. catado: trata-se do café padronizado, por tipo de bebida, conforme o grupo de classificação. Este café é peneirado e selecionado automaticamente em máquinas eletrônicas, que procedem à separação pela cor dos grãos e, assim, apresentam uma aparência padrão, amplamente aceita no mercado interno e externo;

- resíduo: trata-se dos resíduos dos tipos de café selecionados na operação anterior. São considerados resíduos por não apresentarem grãos de tamanho considerado comercial, e também por apresentarem colorações diferentes dos padrões. No entanto, via de regra, produzem a mesma bebida que os anteriores, embora alcancem preços menores, em função de sua aparência mais pobre;

- impurezas: trata-se de materiais inertes e elementos sólidos indesejáveis, presentes no café entregue pelos cooperados como, por exemplo, pedras e gravetos. Esses materiais normalmente são descontados, uma vez que o preço a ser pago ao produtor considera o teor de pureza, ou de "catação".

O café preparado, isto é, selecionado e dividido nas partes descritas anteriormente, é a matéria prima para a elaboração dos blends, no processo conhecido como "liga" de café. A liga é uma mistura de cafés, composta de tipos diversos, de acordo com a preferência do comprador. Os blends podem ser padronizados, no caso de compradores freqüentes, ou desenvolvidos "sob encomenda". Os blends têm de atender a padrões pré-definidos de bebida; o setor de classificação da cooperativa executa uma espécie de "alquimia" para sua elaboração, testando diferentes combinações, que permitam obter a bebida desejada, com o menor custo possível. No caso de elaboração de blends para o mercado externo, além do tipo de bebida, existe uma exigência muito maior quanto à aparência dos grãos: aspecto, cor, tamanho, cheiro, seca, torração, etc.

\section{Bases para a Implantação de um SIG de Custos por Qualidade do Café}

A controladoria , conforme Riccio e Peters (1993), "tem sua missão atrelada ao 
sucesso da gestão econômica, ou seja, deve monitorar as atividades desenvolvidas pela empresa, uma vez que elas possuem o componente econômico embutido. Em sua função de planejamento e controle econômico e da qualidade, deve atentar para o fato de que a maioria das empresas bem sucedidas na competição no mercado global são as que têm assumido firme compromisso com a eliminação de custos das atividades que não adicionam valor ao produto/serviço”.

No novo paradigma, a controladoria deve ser o Centro de Inteligência da Empresa, atuando na orientação e apoio à tomada de decisões dos executivos, e usando uma linguagem comum à toda organização (Riccio e Peters, 1995). Nesta abordagem baseia-se o SIG proposto, entendendo-se que a análise de custos do café por qualidade pode auxiliar a controladoria a verificar o que agrega ou não valor à empresa, e embasar um redirecionamento de atividades.

Na Cooxupé todo lote de café é recebido dos produtores como "matéria-prima", e caracteriza-se por sacas classificadas, que contém um tipo de café (de R.A.), um percentual de café do mesmo tipo e de qualidade inferior, e um percentual bem menor de impurezas, que será perdido. Pode-se admitir que separados os percentuais caracterizados, os cafés idênticos têm o mesmo valor de mercado, embora o preço pago pela seca possa variar muito. A partir daí, admite-se que o controle se possa dar em uma ficha simples de estoque, de entradas e saídas, formando preços médios, uma vez que são idênticos. Deste modo, pode-se conhecer os custos por qualidade, ou por R.A. Assim, a proposta de Gestão de Custos por Qualidade do Café enfoca a criação de um sistema integrado de gerência de estoque que possa controlar todas as quantidades nas várias fases do processo e de acordo com seu estado e posse, considerando seus preços reais.

\section{Modelo Estratégico de Gestão de Custos de Café por Qualidade}

Para maior praticidade e poder de análise, o sistema deverá operar com um número reduzido de tipos de café por qualidade (R.A.), que são os 14 tipos citados anteriormente. $\mathrm{O}$ modelo consiste na análise e proposta de implantação de um sistema gerencial do preparo de café na cooperativa, utilizando o método de apropriação de custos por atividade, custo ABC (activity based costing). Considerando-se que as atividades do armazém se iniciam em um setor e se encerram em outro, apresenta-se um fluxograma dividido em fases/departamentos, buscando facilitar o funcionamento do sistema, enquadrando-o ao método de análise para o custo ABC.

Atendendo às exigências de controle de estoques geralmente aceitos, através de fichas de estoque a preços médios, a proposta apresenta seis fases de controle, diferenciando as fichas por tipo de café. Cada fase de controle vive determinada situação do produto, formando o preço médio, quando estoque próprio e, alimentada por preços de mercado, quando ainda sob detenção do cooperado. A propos- 
ta também desvincula o lote próprio e o lote de cooperado, substituindo este tipo de controle pela característica de cada café. A proposta efetiva encontra-se anexa a este relatório.

\section{Módulo 1: Controle de Estoque do Café do Cooperado}

Nesta fase o café em cada lote guarda as características de catação e impurezas. Os preços deste estoque são os preços de mercado de cada tipo de café. Este controle é muito próximo do que já existe. O controle de estoque por qualidade (R.A.) pode ser representado por:

\section{ENTRADAS}

1. Remessas de café do Cooperado

2. Café em Coco beneficiado na Cooperativa
- Nota Fiscal do Produtor

- Boletim de Produção gerado no armazém

\section{SAÍDAS}

3. Retorno de Café ao Cooperado

4. Compra de Café do Cooperado pela Cooperativa - Nota Fiscal de Venda do Cooperado

\section{Módulo 1}

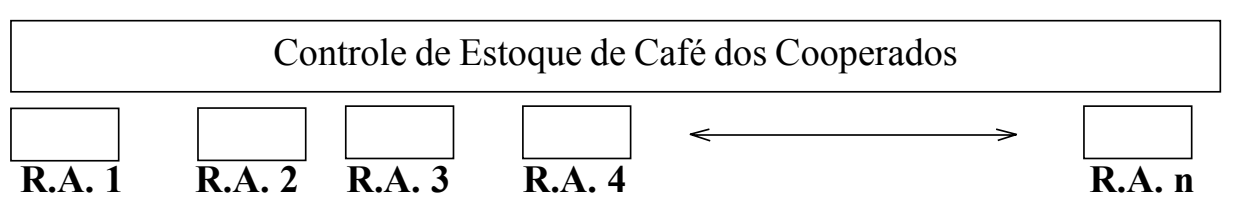

\section{Módulo 2: Controle de Estoque Físico (Café Depositado)}

Esse módulo controla o estoque físico de café, ainda como "bica corrida", admitindo fichas de estoques de um controle comum, mas com uma particularidade: separa cada tipo de estoque em três fichas: "café catado" "café resíduo" e "impurezas". Esta separação é necessária, porque cada parte tem preço diferente e conhecido.

Esta fase do controle trabalha em dois arquivos: o primeiro (2-A) recebe todo o café depositado, e o segundo (2-B) "compra" o café dos cooperados, armazenando-o em estoque físico próprio. Assim, quando for dada uma saída deste estoque para o terceiro grupo de controle (Fase 3), o sistema procura primeiro no estoque 
próprio e complementa as quantidades, se necessário, com café do estoque de cooperados, a preço de mercado.

Por esse critério, o preço de mercado só vai influenciar o custo do produto à medida que diminua a utilização ou o estoque próprio. $\mathrm{O}$ que significa que a não opção de compra pela cooperativa a deixa com maior liquidez, e menos vulnerável às oscilações de preço de mercado. Assim, cada vez que determinado blend de café vendido for composto por muito café próprio e pouco café dos cooperados, o seu custo se aproxima do real (preço pago pela mercadoria). Cada vez que o contrário ocorra, as oscilações de mercado interferem diretamente no custo dos produtos vendidos.

As características citadas no primeiro controle de estoque (Módulo 1) são agora separadas, apresentando as quantidades de cada um com seus valores, identificando com detalhes a posição dos estoques físicos.

Uma instrução de serviço (I.S.) já relaciona a quantidade de café por qualidade (por R.A.) que será utilizado (despejado para ser preparado ou para compor o blend). Menciona ainda quanto de resíduo de cada R.A. será utilizado e a quantidade de impurezas que contém cada café utilizado. Para possibilitar a padronização dos controles, o sistema proposto deve controlar as quantidades em quilogramas, e não em sacas de café, como tradicionalmente é feito.

\section{Controle de Estoque Módulo 2-A:}

\section{ENTRADAS}

1. Remessas de café do Cooperado

- Nota Fiscal do Produtor

\section{SAÍDAS}

3. Retorno de Café ao Cooperado

4. Compra de Café do Cooperado pela Cooperativa - Nota Fiscal de Venda do Cooperado

\section{Módulo 2-A : Estoque de Café Depositado}

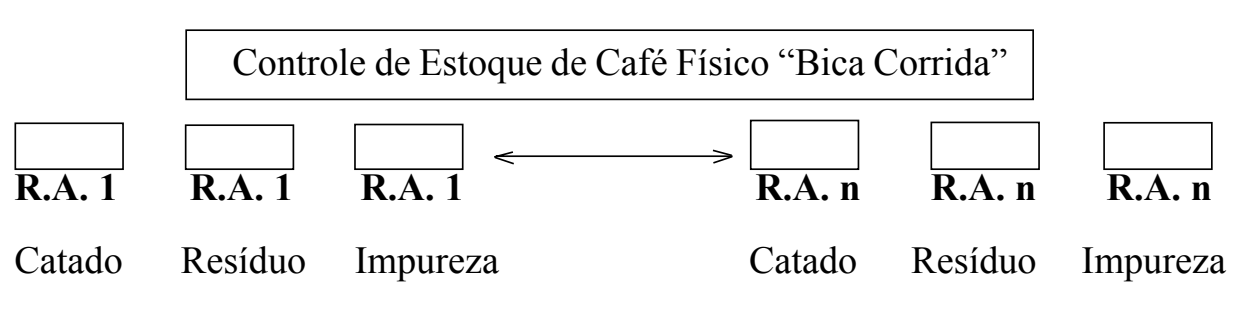




\section{Controle de Estoque Módulo 2-B:}

\section{ENTRADAS}

4. Compra de Café do Cooperado pela Cooperativa - Nota Fiscal de Venda do Cooperado

5. Compra de Café de Terceiros

- Nota Fiscal de Entrada

\section{SAÍDAS}

6. Baixas do Estoque por Instruções de Serviços (I.S.) - Preparo ou Liga (quando direto de "Bica Corrida")

Módulo 2-B : Estoque de Café Próprio (da Cooperativa)

\begin{tabular}{|l|l|l|l|l|l|}
\hline \multicolumn{5}{|c|}{ Controle de Estoque de Café Físico "Bica Corrida" } \\
\hline & & & & \\
\hline R.A. 1 & R.A. 1 & R.A. 1 & R.A. n & R.A. n & R.A. n \\
Catado & Resíduo & Impureza & Catado & Resíduo Impureza
\end{tabular}

Os preços na fase 2 são: preço pago para café já comprado pela cooperativa e preço de mercado para os cafés de cooperado, cada um formando custo médio em seu estoque específico.

\section{Módulo 3: Controle de Estoque de Café Preparado}

Feito a partir de uma instrução de serviços - Produto em Elaboração - recebe o café despejado da Fase 2 e o transforma no novo estoque. Considerando que a Fase 2 já separa as fases, as variações verificadas no processo produtivo representarão perdas ou ganhos sobre os preços originais.

Os preços que este estoque receber serão fixados, ou "congelados", isto é, não sofrerão mais alterações de mercado, mesmo que contenha café de cooperado. $\mathrm{O}$ seu custo se dará por custo médio do estoque.

\section{ENTRADAS}

6. Pelas Instruções de Serviços (I.S.) - de Preparo (direto de "Bica Corrida")

Nesta fase (entrada) o sistema deve buscar produto no estoque físico próprio (a preço médio de compra) e complementa, se necessário, no estoque físico de cooperado (ou terceiros) a preço de mercado. 


\section{SAÍDAS}

7. Pelas Instruções de Serviços (I.S.) - de Liga.

\section{MÓDULO 3 : Produto em Elaboração}

Controle de Estoque de Café Preparado (Físico)

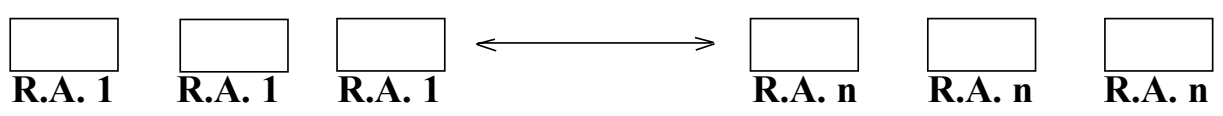

Catado Resíduo Impureza

Perda (nulo)

Catado Resíduo Impureza

Perda (nulo)

\section{Módulo 4: Controle de Estoque de Café Ligado (Blends)}

Esta fase de controle será transitória, porque um blend é quase sempre uma operação de venda concretizada. O sistema registrará os tipos de café por qualidade (R.A.) sem definir características que, nesta fase, já não existem, pois um blend é uma mistura que garante uma bebida homogênea.

\section{ENTRADAS}

8. Instruções de Serviço (I.S.) de liga

\section{SAÍDAS}

9. Vendas de Café

- Nota Fiscal de Venda

Módulo 4

Controle de Estoque de Café Ligado

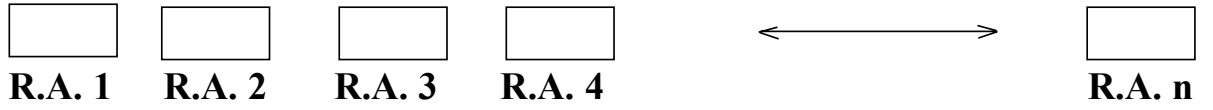

\section{Módulo 5: Controle Analítico da Conta Opção}

Esse controle não formará preço médio no estoque. Acumulará as entradas (por compra de café de cooperados ou de terceiros) e as vendas para clientes, ambos 
por qualidade (R.A.). O saldo desta conta, apesar de não guardar relação com o estoque físico real, apresentará os volumes de cafés por tipos negociados e demonstrará o resultado financeiro das operações comerciais.

\section{ENTRADA}

4. Compra de Café do Cooperado pela Cooperativa - Nota Fiscal de Venda do Cooperado

5. Compra de Café de Terceiros

- Nota Fiscal de Entrada

\section{SAÍDA}

9. Vendas de Café

- Nota Fiscal de Venda

Módulo 5

\section{Controle de Estoque de Café Analítico da Conta Opção}

$\begin{array}{llllll}\square & \square & \square & & & \\ \text { R.A. } 1 & \text { R.A. } 2 & \text { R.A. 3 } & \text { R.A. } 4 & & \text { R.A. } \mathrm{n}\end{array}$

Este SIG de custos e controles, específico para o café, deve ser complementado com subsistemas que garantam a segurança de sua execução e permita que as movimentações aconteçam. Além dos cinco módulos, num total de seis arquivos propostos, deverão ser mantidos os controles já existentes:

1) controle de "contas a pagar" aos cooperados: organizado em lotes de café, forma em que os depósitos são realizados. Deve ser mantido por ser transparente, e seus estoques serão os mesmos propostos na Fase 1;

2) controle de estoque físico: café existente no armazém. Deve ser mantido, uma vez que as baixas das instruções de serviços (I.S.) continuarão sendo feitas em lotes de café.

Para movimentação dos estoques nos arquivos propostos, um sistema complementar deverá acumular em cada instrução de serviço (I.S.) quanto de "café catado", "resíduo" e "impureza" de cada R.A. será utilizado. Com este sistema, as baixas normais, que atualmente já são feitas, alimentarão o sistema proposto. A alimentação de dados do sistema será feita pelo estoque físico de café e pelos "estoques" de café a 
crédito dos cooperados naquela data. A valorização de todo o estoque nas várias estruturas criadas receberá preços de mercado, atualizados diariamente.

\section{CONCLUSÕES}

O Sistema de Informação Gerencial apresentado integra a gestão de estoques com o gerenciamento de custos de café por qualidade. O SIG parte de uma visão ampliada da administração da cooperativa, considerando o trabalho dentro e fora da empresa, relacionando os controles de estoques da cooperativa e do cooperado, físico e "virtual" (estoque do cooperado que a foi utilizado) e o mercado consumidor, possibilitando controle mais eficiente para a redução do risco da cooperativa. O conhecimento das características dos tipos de café por qualidade, que compõem o controle de estoque físico e que faz flutuar a conta opção, traz maior autonomia e segurança.

O SIG atende ao desafio da melhoria contínua da qualidade da gestão, através da visão integrada da empresa, possibilitando o conhecimento real dos custos envolvidos e da margem de lucro por qualidade em cada operação. O sistema proposto gera melhor controle das operações, dos custos dos produtos vendidos, de acordo com sua qualidade e margem de lucro, em cada operação de venda possibilitando melhor planejamento da comercialização pela cooperativa.

Ao propor a implantação integrada de novo modelo de análise de custos por qualidade, o trabalho provocou o exame de vários procedimentos atualmente em uso, preparando o ambiente da empresa para nova mentalidade gerencial. Fez com que procedimentos relacionados com qualidade do café fossem devidamente estruturados no modelo de operação da empresa, servindo de referência para os trabalhos rumo à certificação com as normas Série ISO 9000, exigência do mercado externo. Deste modo, a cooperativa iniciou um processo de melhoria contínua, com a constante identificação de oportunidades, inspecionando-se e atualizando-se índices, levantando-se problemas e propondo soluções.

Este trabalho traz uma colaboração à análise de custos de café por qualidade, contribuindo para a melhoria da administração e do desempenho do setor. Aponta uma oportunidade para dar um avanço para a gerência de custos e riscos, utilizando os custos como instrumento de apoio à Gestão Empresarial Integrada, tornando o setor mais competitivo e de acordo com a nova cultura empresarial e com os padrões de competição de mercado. 


\section{ReferênCias Biblográficas}

AGUIAR, A. F. S. et al.

Integração da manufatura : o caminho para a modernização. Máquinas e Metais, set. 1994.

ARAÚJO, N. B. de;

WEDEKIN, I.;

PINAZZA, L. A.

Complexo agroindustrial - $\mathrm{o}$ agribusiness brasileiro. São Paulo: AGROCERES, 1990.

BARRETO, A. A.

La producción y transferencia de información y la producción de conocimientos. In: ENCONTRO SOBRE GESTIÓN DE INFORMACIÓN (1994 : São Paulo). Anais... São Paulo : CLACSO, 1994.

BERLINER, C.;

BRIMSON, J. A.

Cost management for today's advanced manufacturing. Boston : HBSP, 1988.

CARNEIRO FILHO, F. C.

O planejamento da comercialização pelo produtor. Londrina : Planejamento Cafeeiro, 1989.

COHEN, D.

Sistemas de información para la toma de decisiones. New York : McGraw-Hill, 1996.

\section{CORNELLA, A.}

Los recursos de información. New York : McGraw-Hill, 1994.

EATON, J. J.;

BAWDEN, D.

What kind of resource is information. International Journal of Information
Management, n.11, p.156-65, 1991.

GLAZER, R.

Measuring the value of information - the information intensive organization. IBM Systems Journal, v.32, n.1, p.99, 1993.

HORTON, J. R.;

FOREST, W.

The concepts and trends of information resource management. FID News Bulletin, v.41, n.4, p.71-78, 1991.

INSTITUTO BRASILEIRO DO CAFÉ

Cultura de café no Brasil - manual de recomendações. Rio de Janeiro, 1985.

KAGEYAMA, A. et al. (Coord.)

O novo padrão agrícola brasileiro do complexo rural aos complexos agroindustriais. Campinas : UNICAMP, 1987.

MEGIDO, J. L. T.

Agribusiness : o que é, para que serve, quantos são, e o que o Brasil ganha com isso. Revista da ESPM, v.4, n.1, p.24-28, maio 1997.

\section{OCEMG}

Coleção Ato Cooperativo N.7. Belo Horizonte : Organização das Cooperativas do Estado de MG, 1994.

PÁEZ URDANETA, I.

Gestión de la inteligencia social. Venezuela, 1994. Postgrado (Estudios de la Información) Universidad Simón Bolivar. 
RENTES, A. F. et al.

Uma proposta de uma metodologia de integração de empresa. In: XXXI CONGRESSO LATINO-AMERICANO DE ADMINISTRAÇÃO (1996 : Santiago). Anais... Santiago : CLADEA, 1996.

RICCIO, E. L.;

PETERS, M. R. S.

Novos paradigmas para a função controladoria. In: $17^{\circ}$ ENCONTRO ANUAL DA ANPAD (1993: Salvador). Anais... Salvador : ANPAD, 1993. v.6.

Controladoria e benchmarking : aplicação em uma empresa de classe mundial. Revista Brasileira de Administração Contemporânea, v.1, n.4, p.359-375, set. 1995.

SOARES, P.

Avaliação econômica da política tritícola de 1967 a 1977 . Coleção Análise e Pesquisa, v.20, nov. 1980. 